\title{
Retraction Note to: Lead poisoning in Nile tilapia (Oreochromis niloticus): oxidant and antioxidant relationship
}

Mahmoud Tanekhy

Published online: 7 December 2016

(C) Springer International Publishing Switzerland 2016

Retraction Note to: Environ Monit Assess (April 2015) 187, Issue 4:154

DOI 10.1007/s10661-015-4387-8

This article has been retracted at the request of the Editor-in-Chief. A complaint received against it indicated that it had very high levels of similarity to text, study design and figures with the following article:

Nephroprotective and antioxidant significance of selenium and $\alpha$-tocopherol on lead acetate-induced toxicity of Nile Tilapia (Oreochromis niloticus), (2015),
Hashish, E.A., Elgaml, S.A., El-Murr, A., Khalil, R, 41: 651. Fish Physiology and Biochemistry, June 2015, Volume 41, Issue 3, pp 651-660.

An investigation carried out by the Vice President of Graduate Studies and Research at Alexandria University found that the research presented in the EMAS paper by Mahmoud Tanekhy was published without the consent of the original owners of the work - Dr. Ryad Khalil (Alexandria University) and Drs. Emad A. Hashish, Dr. Shimaa A. Elgaml and Dr. Abdelhakeem El-Murr (Zagazig University).

The online version of the original article can be found at http://dx. doi.org/10.1007/s10661-015-4387-8.

M. Tanekhy $(\bowtie)$

Department of Poultry and Fish diseases, Faculty of Veterinary Medicine, Alexandria University, Edfina, Rosetta 22758, Egypt e-mail: tanekhyvet2020@yahoo.com 